STUDI

FRANCESI

\section{Studi Francesi}

Rivista quadrimestrale fondata da Franco Simone

143 (XLVIII | II) | 2004

Varia - fasc. II - maggio-agosto 2004

\title{
Thomas Vauterin, Impossibilité et écriture dans «Fragments d'un discours amoureux»
}

\section{Stefano Costa}

\section{(2) OpenEdition}

Journals

\section{Edizione digitale}

URL: https://journals.openedition.org/studifrancesi/39802

DOI: 10.4000/studifrancesi.39802

ISSN: 2421-5856

\section{Editore}

Rosenberg \& Sellier

\section{Edizione cartacea}

Data di pubblicazione: 1 décembre 2004

Paginazione: 411

ISSN: 0039-2944

\section{Notizia bibliografica digitale}

Stefano Costa, «Thomas Vauterin, Impossibilité et écriture dans «Fragments d'un discours amoureux»», Studi Francesi [Online], 143 (XLVIII | II) | 2004, online dal 30 novembre 2015, consultato il 19 mai 2021. URL: http://journals.openedition.org/studifrancesi/39802; DOI: https://doi.org/10.4000/studifrancesi. 39802

Questo documento è stato generato automaticamente il 19 mai 2021.

\section{(c) $(1) \ominus$}

Studi Francesi è distribuita con Licenza Creative Commons Attribuzione - Non commerciale - Non opere derivate 4.0 Internazionale. 


\title{
Thomas Vauterin, Impossibilité et écriture dans «Fragments d'un discours amoureux»
}

\author{
Stefano Costa
}

\section{NOTIZIA}

THOMAS VAUTERIN, Impossibilité et écriture dans «Fragments d'un discours amoureux» -

Fictions du savoir à la Renaissance «Littératures» n. 47, 2002, pp. 155 - 167.

1 L'opera in questione, per la sua natura frammentaria, ha sempre posto nel corso degli anni problemi di analisi così come difficoltà di lettura in quanto spesso erroneamente considerata discontinua. L'analisi dell'A. tende a dimostrare come tale frammentazione rappresenti, in realtà, la ricerca di un metalinguaggio mirato a rendere per iscritto la sensazione di un sentimento così etereo e quasi 'impossibile' da descrivere come è l'amore ed i comportamenti che ne conseguono. In Fragments d'un discours amoureux emergerebbero, infatti, tre figure che l'A. considera la chiave di lettura di un'opera innegabilmente complessa: cacher, écrire e obscène. Il soggetto si trova in uno stato emotivo in cui esita tra il mostrare ed il nascondere la propria passione volgendo, successivamente, nel desiderio di esprimere il sentimento amoroso attraverso la creazione, la scrittura, che, per quanto artificiale ed incapace di rendere la vérité de l'amour, rappresenta il codice. Un codice tuttavia rifiutato nell'intento di evitare la banalizzazione letteraria di un sentimento che trova risposta nell' obscène dove l'indecenza non è più rappresentata dalla sessualità ma dal sentimentale. 